\title{
Explaining Incomplete Contracts as the Result of Contract-Reading Costs
}

September 3, 2001. Retexed 13 Dec. 2006.

PUBLISHED IN: the BE Press journal, Advances in Economic Analysis and Policy. Vol. 1: No. 1, Article 2 (2001). http:/ / www.bepress.com/bejeap/advances/vol1/iss1/art2.

\section{Eric Rasmusen}

\section{Abstract}

Much real-world contracting involves adding finding new clauses to add to a basic agreement, clauses which may or may not increase the welfare of both parties. The parties must decide which complications to propose, how closely to examine the other side's proposals, and whether to accept them. This suggests a reason why contracts are incomplete in the sense of lacking Pareto-improving clauses: contract-reading costs matter as much as contract-writing costs. Fine print that is cheap to write can be expensive to read carefully enough to understand the value to the reader, and especially to verify the absence of clauses artfully written to benefit the writer at the reader's expense. As a result, complicated clauses may be rejected outright even if they really do benefit both parties, and this will deter proposing such clauses in the first place.

Professor of Business Economics and Public Policy and Sanjay Subhedar Faculty Fellow, Indiana University, Kelley School of Business, BU 456, 1309 E. 10th Street, Bloomington, Indiana, 47405-1701. Office: (812) 855-9219. Fax: 812-855-3354. Erasmuse@indiana.edu.

I thank Maria Arbatskaya, William Bright, Lutz Busch, Peter Cramton, Kenneth Elzinga, T. Lynn Fisher, Benjamin Hermalin, Michihiro Kandori, Felice Martinello, Wolfgang Pesendorfer, J. Mark Ramseyer, David Waterman, two anonymous referees and participants in seminars at Brock University, CIRANO (Montreal), Indiana University, the U. S. Department of Justice, Kyushu University, the University of Manitoba, Otaru University of Commerce, the Central Bank of Turkey, Virginia Polytechnic Institute, the University of Virginia, and the American Law and Economics Association for helpful comments. I thank Harvard Law School's Olin Center and the University of Tokyo's Center for International Research on the Japanese Economy for their hospitality. Not all of those I thank have seen this draft, and they bear no responsibility for errors. 


\section{INTRODUCTION}

Why are contracts incomplete? The contracts we observe in the world often fail to specify what happens in many important contingencies and they are not always crafted to provide each party with the optimal incentives. This has been often remarked upon, notably in Stewart Macaulay's classic 1963 article, "Non-Contractual Relations in Business: A Preliminary Study."

Some contractual incompleteness can be explained easily enough. Important aspects of the agreement are unobservable to one of the parties (information is asymmetric) or too costly to prove in court (information is "unverifiable") . These things can then induce a "second-best" effect: the parties decide to omit from the contract certain of even the observable variables for fear of unduly concentrating incentives on just what is included. ${ }^{2}$ Or, it may be desirable to leave something out of the contract so it can be used as a threat by a party who would otherwise be vulnerable to opportunism by the other party (B. Douglas Bernheim \& Michael Whinston, 1998). ${ }^{3}$

Asymmetric information can also lead to incomplete contracts in a different way: Party A's fear that if he proposes an addition to the contract Party B will deduce that he has private information and either be more reluctant to trade or somehow use that information against him. If a professional athlete asks for extra health insurance from his employer, for example the employer may deduce, rightly or wrongly, that the athlete is not feeling well and propose a lower salary. If an industrial buyer asks for a minimum monthly quantity guarantee in a long-term contract, the seller may deduce-again, rightly or wrongly - that the buyer does not have alternative sources of supply, and raise the price. This idea can be found in a number of contexts, including the models of Ian Ayres and Robert Gertner (1992), Benjamin Hermalin and Michael Katz (1993), and Kathryn Spier (1992).

On a simpler level, there is a cost to deciding which contingencies are important and to writing the contract clauses themselves. And even if the parties write a simple contract, if the

\footnotetext{
${ }^{1}$ If information is symmetric but unverifiable-observed by both parties to the contract but unobservable to the court - then it may still be useful to design an agreement around that information, as the mechanism design literature tells us. This possibility brings into question unverifiability as an explanation for contract incompleteness, a controversy discussed in Jean Tirole (1999).

${ }^{2}$ This is the idea in Bengt Holmstrom and Paul Milgrom (1991). Suppose an employment contract specifies that a salesman will (a) work 40 hours per week, and (b) be paid based on his sales volume. This contract omits the variable "time spent helping other salesmen", which is unobservable to the employer or to the court. As a result, the salesman will spend zero hours helping other salesmen, and a better contract might omit part (b).

${ }^{3}$ Bernheim and Whinston's article provides a bridge to a separate literature, on renegotiation in contracts. Many of these articles in that literature have "incomplete contracts" in the title but they are about the consequences, not the causes, of incompleteness. Examples are Oliver Hart \& John Moore's 1988 "Incomplete Contracts and Renegotiation," Tai-Yeong Chung's 1991 "Incomplete Contracts, Specific Investments, and Risk Sharing," and Christoph Lulfesmann's 2001 "Incomplete Contracts, Non-Contractible Quality, and Renegotiation." A second-best explanation for incomplete contracts in the spirit of this literature would be that future renegotiation on unverifiable variable $X$ makes it undesirable to include verifiable variable $Y$ in the initial contract. I do not recall seeing this in a formal model, however, and mention it only as a conjecture.
} 
dispute goes to court, the court will "fill in the blanks" using default rules designed to work well for the typical contract. In a sense, it is impossible to write an incomplete contract, because the courts will always find some way of interpreting a contract for every contingency. With the addition of the law's implicit default rules, even a very short contract is extraordinarily complex in its legal implications.

Thus, we do have a number of explanations for why important variables are left out of contracts-unobservability, unverifiability, second-best incentives, fear of signalling undesirable characteristics, contract-writing costs, and legal default rules. These explanations are far superior to the old phrases, "bounded rationality" and "transaction costs," in that they explain which contracts will be most complete, but for that very reason they leave us with many contracts which ought to be complete but are not. ${ }^{4}$ Often the contingencies omitted in the contract are easily verifiable in court-disasters, accidents, changes in market prices, and so forth. Often there is no problem of distorted incentives. Writing down details of the agreement has low cost if the contractual situation is repeated and there are economies of scale, as when a retailer sells to a thousand consumers. Once the contract is written, writing extra sentences adds little to the cost. And though courts do their best to fill in the blanks, existing legal default rules will be tailored for the average contract and thus will not fit every contract. And if the courts have not encountered a particular blank in a contract before, they will make up a new default rule, which adds uncertainty to the original agreement.

I will suggest a new explanation: contract-reading costs. The problem is not in the social cost of discovering or writing a new contract term, nor is there any problem with incentives, commitment, or enforcement once the contract is formed. Rather, the problem is that Party A cannot understand the implications of language proposed by Party B unless he expends effort reading the contract carefully. Contracts are thus incomplete because both parties must agree to them, the problem lying in the contract-forming process that I will call negotiation. Economists usually think of contract formation as bargaining over splitting a pie, but it can increase the size of the pie, which is what we think extra contract terms could do.

Examples abound. If I negotiate with a contractor about building a house, we do not just talk about the price, and our talk about the details of the contract is not just redistributive. We could eliminate almost all the contracting costs if the government were to require that houses be of a single standard design, but that would not be efficient. I have my particular preferences about the windows, woodwork, floor type, color, and time of completion, and the contractor has his own individual costs for each feature. Much of my concern will not be about whether I can extract a good price at the expense of the contractor, but whether I am agreeing to buy features of the house that I really want. Rather than agree to builder proposals that sound attractive, I may wish to leave some features out of the contract, to be determined by default legal rules.

\footnotetext{
${ }^{4}$ Any of the explanations for incompleteness just given could fit under the heading of either "bounded rationality" or "transaction costs," since those headings amount to little more than residuals for whatever makes behavior different from in the simplest maximizing models.
} 
Labor contracting is dominated by negotiation of this kind. It may be that a union and an employer have agreed upon a wage, but that does not end the collective bargaining. The employer may also offer an extension to the health insurance benefits, in exchange for a wage concession. Possibly, the benefit to the union is greater than the lost wages, in which case the change would benefit both sides. Or, maybe the workers could do better by rejecting the new insurance. The union negotiator's uncertainty is not over the minimum offer acceptable to the company, but over whether the health insurance helps both sides.

Or consider mergers and acquisitions, notoriously complicated deals. Suppose company A is selling off a division to company B. They have agreed on a price, but now company A asks that a clause be added to the deal under which it would buy back a certain amount of the output of the division each year at a specified price. The clause might benefit company B, or might hurt it. Again, the uncertainty is not over the minimum that company A would accept, but over whether the contract benefits both sides or not. It may be quite clear that the clause benefits company A by exactly five million dollars, but it may be unclear what the cost is to company $\mathrm{B}$.

On a less grand level, suppose that Mr. Smith is selling a load of lumber to Mr. Jones. After the deal has been made, Smith says, "Throw in an extra $\$ 50$ and I'll deliver the lumber to your house. It's no big deal for me, and you'll save a lot of effort." Jones's uncertainty is not over the cost of delivery to Smith, which is of no interest to him. Rather, it is over the net benefit to himself. The cost of hiring a deliveryman might be $\$ 80$, in which case Smith is right that both Smith and Jones would benefit from the proposal, or it might be $\$ 30$, in which case Smith gains but Jones loses.As an alternative, the contract might be left incomplete, with delivery left for later decision.

All four examples involve the conflict between production and distribution which is emphasized in the nonformal literature on bargaining, where it is called the conflict between "creating value" and "claiming value" (see the 1992 survey by James Sebenius). This difference has been recognized but not modelled. At the start of their 1993 survey of bargaining models John Kennan and Robert Wilson list three costs of bargaining:

"Costly delays and failures to agree when gains from trade exist represent two kinds of inefficiencies; a third is that an agreement is inefficient if its terms fail to realize all the potential gains from trade, as in the case that a firm's contract with a union specifies inefficient work rules or numbers of workers."

Kennan and Wilson go on to survey the bargaining literature at length, but while costly delays and failures to agree receive ample attention in the next fifty-eight pages, failure to realize all the potential gains from trade does not resurface.

I will explore contract-reading costs as a reason for the failure to realize all the gains from trade. A complicated contract is relatively easy to write, but it is difficult to read. By reading I do not, of course, mean simply staring at words, or even looking at each word and understanding what it means in isolation. Rather, the problem is to read the contract and understand its implications. Even unsophisticated parties to contracts know that by signing their name they 
are making themselves vulnerable, and that the other parties are self-interested. Reading is a skill, and requires effort even by those who are expert in it. As George Stigler points out in his 1980 article on privacy, apparently free information is actually costly once we include the effort of understanding how to use it. His example is what might seem the paradigm of information as a public good: the mathematical theorem.

"Consider the highly useful solution of the quadratic equation $\left(x=-b \pm \sqrt{b^{2}-4 a c} / 2 a\right)$. It was discovered by numerous mathematicians, probably at small cost.[Footnote omitted] To make it available to our society, we invest perhaps a day of every high school student's life in instructing them in its use. The social costs of nonrecovery of the original discovery are contemptibly negligible compared to any inefficiencies in the dissemination of the theorem." (Stigler, 1980, Appendix A)

Like mathematical theorems, legal clauses can be copied from books. The clauses can easily be read out loud and even memorized without great difficulty. But that does not mean they are easy to understand. And even small reading costs have wide-ranging implications, as we will see below.

Previous research has not touched upon contract-reading costs, though it has come close enough that the formal analysis of the next section will not require any new modelling technology. The central idea of the present paper-that a party's proposal of a more complex contract should be viewed with suspicion because of possible underlying implications - is related to the articles by Ayres \& Gertner (1992), Hermalin \& Katz (1993), and Spier (1992) cited earlier, in which complex contract proposals signalled undesirable characteristics of the proposer, leaving him worse off than if he had remained silent. Here, however, complex contract proposals will signal nothing about the proposer, though they may signal something about the contracts themselves. If the proposals are rejected, the proposer will be no worse off than if he had remained silent, except for having expended contract-writing costs. Moreover, the party to whom a proposal is made will have the opportunity to obtain information directly by incurring the contract-reading cost rather than just by deduction.

The closest model to the present one is perhaps that of Avery Katz (1990). Katz is not concerned with negotiation per se, but with the legal rules involving the fine print in contracts (incidentally, the same issue as in the 1993 article by Benjamin Hermalin and Michael Katz cited earlier). The courts must decide how much fine print to enforce. If they enforce none of it, they must specify how the contract binds the parties, because the writing in the contract has been abandoned. If they enforce all of it, each party must read the terms carefully or abandon detailed contracts in favor of short but ambiguous ones. The legal rules should be designed to induce the parties to monitor what each inserts into the contract.

Attention in the present paper, however, will be on what the contractors will do rather than on what the courts should do. Courts will make no effort here to determine what is fair or whether both parties fully understood their agreement. Rather, if both parties agree to the 
contract, the courts will enforce it as written, even if it is clear later that one party did not read it carefully.

The framework will be an auditing model. In such a model, one player takes an action which the other player can either audit or let pass. Here, the action will be to insert an extra clause in the contract, a clause which might benefit both players, creating value, or just benefit the offeror, claiming value. The other player must decide whether to trust the offer or read it carefully. It will be costly both to offer and to read clauses, so this will be a model both of contract-writing and contract-reading costs.

The strategic problem is thus different from in bargaining or mechanism design. In bargaining, a player's concern is to determine how much the pie is worth to the other player so he can offer a share just big enough for the deal to go through. In mechanism design, the mechanism tries to elicit from each player his private information: the value of the pie to himself. In the model here, the proposing player will have an incentive to offer the clause regardless of his private information, and the other player will have no private information to elicit. In addition, every new term of a complicated mechanism would just multiply the original problem, by creating new possibilities for redistribution that would themselves have to be examined carefully.

Early applications of auditing were to arms control verification, as in Melvin Dresher (1962). Rudolf Avenhaus, Bernhard von Stengel \& Shmuel Zamir (2002) survey the literature in Volume III of the The Handbook of Game Theory with systematic attention to the variety of auditing situations-only one possible violation but $n$ periods of possible reading, $m$ possible violations and $n$ possible readings, and so forth. One strand of the applied literature, which began with Stan Baiman \& Joel Demski (1980), examines the incentives for high effort by a worker whose income is observed and can be used as the basis for an audit investigation. Another strand, which began with Robert Townsend (1979), investigates the mechanism design question of how a provider of capital can elicit truthful reports of financial condition from the user of capital. Since the problem is one of mechanism design, the players can contract in advance on penalties for lying and bonuses for telling the truth. This kind of auditing, in which lying is penalized, certainly is helpful for negotiation. If someone makes a false claim that can be proved in court, the deal can be voided and criminal penalties may even be applicable. It does not apply, however, to negotiating proposals in which Party A makes a proposal for Party B's consideration without specific claims verifiable in court as to how much Player B will benefit. If a housebuilder says that his customer will like purple paint and that turns out to be false, how is a court to tell whether the customer's complaint is justified? The model used below will not have penalties for lying, and so will have more of the flavor of auditing in politics (e.g., Rasmusen, 1993), where a player's claim can be checked and disproved, but the only penalty is that he has wasted his effort in making the claim.

Section 2 will construct the model of negotiation without solving for the equilibrium. Sections 3 and 4 will find the equilibria in the simple but important cases when precommitment is possible-in Section 3 when a player can precommit to honesty; and in Section 4 when he can 
precommit to reading all clauses carefully. Section 5 is the heart of the analysis, setting out the two equilibria of the game without precommitment. Section 6 contrasts the basic complete- information model with a model of incomplete information. Section 7 , perhaps the most important part of the paper, interprets the model's results at length. Section 8 is a short summary. 


\section{THE MODEL}

Two parties, the "offeror" and the "acceptor," are trying to agree on the details of a contract after having already agreed to its basics. The basic contract will not affect the model and is included only to emphasize that some parts of the deal may not require negotiation. Let us assume that as part of the bargaining process behind the original deal, the players split the anticipated gains from trade equally, including the gains they anticipate from the details added by a new clause in the negotiation subgame being modelled here. We will denote the expected payoffs of the subgame starting with the offer of a new clause by $\pi_{\text {offeror }}$ and $\pi_{\text {acceptor }}$.

The offeror has the option of not offering any clause at all, for a payoff of 0 . Instead, he can offer a "sincere" clause which yields him $x_{s}$ if accepted, or a "misleading" clause which yields him $x_{m}$. The cost to him of making an offer is a contract-writing cost of $c_{w s}>0$ or $c_{w m}>0$, depending on the type of clause. We will not make any assumption on the relative sizes of $c_{w s}$ and $c_{w m}$; it might be more costly to discover and propose a mutually beneficial sincere clause, or to discover and disguise a one-sided clause. We will, however, assume that

$$
x_{m}-c_{w m}>x_{s}-c_{w s}>0 .
$$

The first inequality in (1) says that the offeror would prefer a misleading clause to a sincere one if both had equal probabilities of acceptance, even given the contract-writing costs. The second inequality says that either type of clause helps the offeror if accepted.

The acceptor's benefit is $y_{s}>0$ from a sincere clause and $-y_{m}<0$ from a misleading one. He cannot costlessly identify which clause has been offered. Instead, he can accept it outright, reject it outright, or read it at contract-reading $\operatorname{cost} c_{r}$ to discover whether it is sincere or misleading. Let us assume that

$$
x_{s}+y_{s}-c_{w s}>x_{m}-y_{m}-c_{w m} .
$$

Assumption (2) says that the sincere clause is efficient; there is no side payment that the offeror would be willing to make that would induce the acceptor to knowingly accept a misleading clause.

The order of play is thus

(0) Offeror and acceptor split the expected social surplus of $E\left(\pi_{\text {offeror }}+\pi_{\text {acceptor }}\right)$ from the negotiation subgame equally, using the appropriate side payment of

$$
S=E\left(\pi_{\text {offeror }}\right)-\frac{E\left(\pi_{\text {offeror }}+\pi_{\text {acceptor }}\right)}{2}
$$

from offeror to acceptor, where $S$ might be negative.

(1) The offeror offers a sincere clause at $\operatorname{cost} c_{w s}$ or a misleading clause at cost $c_{w m}$. 
(2) The acceptor reads the clause at cost $c_{r}$, discovering whether it is sincere or misleading, or does not read it.

(3) The acceptor accepts or rejects the clause.

(4) The contract is finalized, payoffs are received, and the effect of the clauses is discovered.

This is a game of complete information. At the start of the game the players possess exactly the same information, and the only way information becomes asymmetric is that once the offeror offers a clause he knows what kind of clause he offered. There do not exist different types of offerors, and there is nothing for the acceptor to learn about the offeror or the state of the world during the game. We will, however, see in Section 6 how an incomplete information version of this model would work.

3.

\section{THE VALUE OF A REPUTATION FOR HONESTY: WHAT IF THE OFFEROR CAN PRECOMMIT?}

What happens if the offeror can precommit to offer only sincere clauses? The acceptor will then not bother to read the clause and will accept it outright. The payoffs are

$$
\pi_{o f f e r o r}=x_{s}-c_{w s}
$$

and

$$
\pi_{\text {acceptor }}=y_{s}
$$

for a total social surplus of

$$
\pi_{\text {offeror }}+\pi_{\text {acceptor }}=x_{s}+y_{s}-c_{w s} .
$$

The social surpluses in this and the scenarios below are tabulated later in Table 1 in Section 5 for comparison. The social surplus in this scenario is the highest possible, because reading contracts is unnecessary and the sincere clauses are always offered.

It is hard to see how someone could literally commit to offering only sincere clauses but in some cases plausible ways to reach the same outcome are available. If the offeror repeatedly negotiates over time with one or different acceptors, he may wish to preserve a reputation for sincerity. If he ever offered a misleading contract, it would be accepted, but if he tried to enforce it, he could lose his reputation.

4.

THE VALUE OF A REPUTATION FOR READING CONTRACTS CAREFULLY: WHAT IF THE ACCEPTOR CAN PRECOMMIT? 
What happens if the acceptor can precommit to read the clause? The offeror will respond by offering a sincere clause, even if he himself cannot precommit as in Section 3. The payoffs are

$$
\pi_{o f f e r o r}=x_{s}-c_{w s}
$$

and

$$
\pi_{\text {acceptor }}=y_{s}-c_{r}
$$

for a total social surplus of

$$
\pi_{\text {offeror }}+\pi_{\text {acceptor }}=x_{s}+y_{s}-c_{w s}-c_{r} .
$$

Given that the side-payment $S$ at the start of the game splits the gains from trade, the acceptor is willing to precommit to reading if expression (9) is positive. It will be positive if the contractreading $\operatorname{cost} c_{r}$ is not too large, a reasonable condition, but one not assumed as part of the model.

The acceptor may be able to do even better, however, as Wolfgang Pesendorfer pointed out to me. Suppose he can precommit to read with auditing probability $\alpha$; e.g., he precommits to read the clause with a probability of 90 percent. This is cheaper than the 100 percent probability used above and it will still deter the offeror from trying to sneak by a misleading clause if

$$
\pi_{\text {offeror }}(\text { sincere })=x_{s}-c_{w s} \geq \pi_{o f f e r o r}(\text { misleading })=(1-\alpha) x_{m}+\alpha(0)-c_{w m},
$$

which requires that

$$
\alpha \geq \frac{\left(x_{m}-c_{w m}\right)-\left(x_{s}-c_{w s}\right)}{x_{m}} .
$$

Assumption (1) ensures that the right-hand side of (11) is between zero and one. If $\alpha$ is set at the lowest level which makes inequality (11) true then the payoffs are

$$
\pi_{o f f e r o r}=x_{s}-c_{w s}
$$

and

$$
\pi_{\text {acceptor }}=y_{s}-\left(\frac{\left(x_{m}-c_{w m}\right)-\left(x_{s}-c_{w s}\right)}{x_{m}}\right) c_{r},
$$

for a total social surplus of

$$
\pi_{\text {offeror }}+\pi_{\text {acceptor }}=x_{s}+y_{s}-c_{w s}-\left(\frac{\left(x_{m}-c_{w m}\right)-\left(x_{s}-c_{w s}\right)}{x_{m}}\right) c_{r} .
$$

The use of the probability $\alpha$ does not imply that the equilibrium is in mixed strategies. Precommitment to an auditing probability is distinct from a mixed strategy because the acceptor must read with positive probability even though he knows that in equilibrium the offeror will never offer a misleading clause. ${ }^{5}$ Without precommitment, if the acceptor announced he was

\footnotetext{
${ }^{5}$ For more on the distinction between auditing and mixing, see Rasmusen (2001), pages 79-81
} 
following the strategy just described it would not be an equilibrium. If the offeror believed the announcement and offered a sincere clause, the acceptor would change his mind and reset the reading probability to zero when the time came to pay the reading cost.

Precommitment might take the form of paying for contract reading in advance of the negotiationby hiring an in-house lawyer and being careful to not have other uses for his time, for example. An interesting alternative would be for the offeror to pay for the lawyer, bundling together the offer of a new clause and the reading of the clause. "He who pays the piper calls the tune," however, and such an arrangement might not be trusted by the acceptor.

The usual substitute for precommitment, reputation, runs into more difficulty here than in Section 3, where I suggested it as way for the offeror to make his honesty credible. Here in Section 4 , the reputation would be the acceptor's reputation for reading contracts carefully. If the acceptor can persuade offerors that he does read contracts carefully, he can maintain such a reputation, but such persuasion may be difficult. Since only sincere clauses are offered in equilibrium, neither a diligent contract reader nor a deviant non-reader would ever find a misleading contract. How, then, could outsiders tell whether the acceptor was really reading them? Verifying that the acceptor is following equilibrium behavior becomes especially difficult when that behavior is to read with probability $\alpha$ less than one, since in each negotiation round, the acceptor could fail to read and claim that his failure was a matter of chance.

If the acceptor can somehow commit to read every offer, however, the social surplus is almost as high as when the offeror can commit to offering sincere clauses. The only difference is the cost of reading.

\section{EQUILIBRIA WITHOUT PRECOMMITMENT}

Let us now assume that neither player can precommit to any action. The offeror might offer either kind of clause and the acceptor might or might not read the fine print of each clause offered.

Any equilibrium must have the following properties:

(a) The offeror does not offer a misleading clause with probability one. If it were known he did this, the acceptor would always reject outright, and so the offeror would incur the contractwriting cost $c_{w m}$ for no benefit.

(b) The offeror does not offer a sincere clause with probability one. If he did, the acceptor would never read the clause, and so the offeror would deviate to offering a misleading clause to obtain $x_{m}-c_{w m}$ instead of $x_{s}-c_{w s}$.

(c) The acceptor does not have probability one of accepting without reading. If he did, the offeror would only offer misleading clauses. 
(d) The acceptor does not read with probability one. If he did, the offeror would never offer misleading clauses, making the reading pointless.

(e) The acceptor does not mix between accepting and rejecting. The offeror would respond by always choosing misleading clauses, which point (a) says cannot happen.

(f) The acceptor does not mix between reading and rejecting. Then no misleading offer would have any hope of being accepted. The offeror would respond by always choosing sincere clauses, which point (b) says cannot happen.

Points (a) through (f) leave two possible equilibria. In the first, both players use mixed strategies.

$$
\text { THE MIXING EQUILIBRIUM (if } c_{r} \leq \frac{y_{s} y_{m}}{y_{s}+y_{m}} \text { ) }
$$

Offeror: Offer the sincere clause with probability $p_{s}^{*}=1-\frac{c_{r}}{y_{m}}$ and the misleading clause otherwise.

Acceptor: Accept without reading with probability $p_{a}^{*}=\frac{x_{s}-c_{w s}+c_{w m}}{x_{m}}$. Otherwise read the clause, and accept it only if the offer is sincere.

Let the probability that the offeror offers the sincere clause be $p_{s}$ and the probability that the acceptor accepts without reading be $p_{a}$. The offeror's pure-strategy payoffs are

$$
\pi_{\text {offeror }}(\text { sincere })=-c_{w s}+p_{a} x_{s}+\left(1-p_{a}\right) x_{s}
$$

and

$$
\pi_{\text {offeror }}(\text { misleading })=-c_{w m}+p_{a} x_{m}+\left(1-p_{a}\right) \cdot 0,
$$

since the misleading clause will be rejected if the acceptor chooses to read. If there is to be a mixed strategy equilibrium, the two pure-strategy payoffs must be equal, so

$$
-c_{w s}+p_{a} x_{s}+\left(1-p_{a}\right) x_{s}=-c_{w m}+p_{a} x_{m}
$$

and

$$
p_{a}^{*}=\frac{x_{s}-c_{w s}+c_{w m}}{x_{m}}
$$

The acceptor's pure-strategy payoffs are

$$
\pi_{\text {acceptor }}(\text { accept })=p_{s} y_{s}-\left(1-p_{s}\right) y_{m}
$$

and

$$
\pi_{\text {acceptor }}(\text { read })=-c_{r}+p_{s} y_{s}-\left(1-p_{s}\right) \cdot 0
$$


since the misleading clause will be rejected if the acceptor reads it. If there is to be a mixed strategy equilibrium, the two pure-strategy payoffs must be equal, so

$$
p_{s} y_{s}-\left(1-p_{s}\right) y_{m}=-c_{r}+p_{s} y_{s},
$$

and

$$
p_{s}^{*}=1-\frac{c_{r}}{y_{m}} .
$$

For the probabilities in (18) and (22) to remain between zero and one requires that

$$
x_{s}-c_{w s}+c_{w m} \geq 0,
$$

which is guaranteed by assumption (1), and

$$
c_{r} \leq y_{m} .
$$

If assumption (24) is false, the Mixing Equilibrium does not exist; the acceptor would never wish to read the clause even as part of a mixed strategy.

We must also check for another possible deviation from equilibrium: the acceptor has the option to reject the clause without reading it, for a payoff of 0 . Comparing the payoff of 0 to the payoff in (20) from the pure strategy of reading the clause (which is $-c_{r}+p_{s} y_{s}$ ), it is apparent that for him to refrain from outright rejection requires that

$$
c_{r} \leq p_{s} y_{s} .
$$

Substituting in (25) for the equilibrium level of $p_{s}$ from (22) and solving for $c_{r}$ yields

$$
c_{r} \leq \frac{y_{s} y_{m}}{y_{s}+y_{m}}
$$

If condition (26) is false, then the Mixing Equilibrium does not exist. Note that condition (26) implies that $c_{r}<y_{s}$. Reading must be cheap enough relative to the value of a sincere clause that the acceptor is willing to undertake the amount of reading needed to give the offeror incentive to sometimes offer the sincere clause. Condition (26) also implies condition (24), that $c_{r}<y_{m}$, which it therefore subsumes.

Using the equilibrium mixing probabilities we can compute the equilibrium payoffs. From equation (15),

$$
\pi_{\text {offeror }}^{*}=x_{s}-c_{w s},
$$

which is non-negative by assumption (1). From (20) and (22),

$$
\pi_{\text {acceptor }}^{*}=y_{s}-c_{r}\left(1+\frac{y_{s}}{y_{m}}\right),
$$


which is non-negative if condition (26) is true and the equilibrium exists. The total social surplus is thus

$$
\pi_{o f f e r o r}^{*}+\pi_{a c c e p t o r}^{*}=x_{s}+y_{s}-c_{w s}-c_{r}-\frac{c_{r} y_{s}}{y_{m}} \geq 0,
$$

which is less than the surplus when the acceptor can precommit to reading every offer.

There also exists a second equilibrium, which is in pure strategies.

\section{THE NO-OFFER EQUILIBRIUM}

Offeror: Do not offer either clause.

Acceptor: Reject any clause that is offered.

of-equilibrium belief: If the offeror deviates and offers a clause, the acceptor believes it is sincere with a probability $\beta$ of no more than $\operatorname{Max}\left\{\frac{y_{m}}{y_{s}+y_{m}}, \frac{c_{r}}{y_{s}}\right\}$.

Neither player has incentive to deviate from the No-Offer Equilibrium. The offeror has no incentive to offer clauses if the acceptor always rejects, and the acceptor has no incentive to read or accept the clause given his beliefs. The dilemma is similar to the situation in some signalling and coordination games, but here unlike in those games (e.g., In-Koo Cho \& David Kreps (1987), Eric Van Damme (1989)), the intuitive criterion and forward induction have no bite. ${ }^{6}$

The out-of-equilibrium beliefs needed to sustain the No-Offer Equilibrium are obtained as follows. If $\beta$ is the acceptor's subjective probability that the offeror's out-of-equilibrium offer is sincere, then the acceptor's subgame payoff is

$$
\pi_{\text {acceptor }}(\text { accept })=\beta y_{s}-(1-\beta) y_{m},
$$

which yields $\beta=\frac{y_{m}}{y_{s}+y_{m}}$ for the value of $\beta$ which makes the acceptor prefer to reject and receive the payoff of 0 .

It must also be true that the acceptor does not think it worthwhile to read the clause. The payoff from reading, given the belief $\beta$, is

$$
\pi_{\text {acceptor }}(\text { read })=\beta y_{s}-(1-\beta)(0)-c_{r},
$$

which yields $\beta=\frac{c_{r}}{y_{s}}$ for the value of $\beta$ which makes the acceptor prefer to reject and receive the payoff of 0 .

${ }^{6}$ If a small number of honest offerors will never make misleading offers (i.e., $c_{w m}=\infty$ for them), then the NoOffer Equilibrium breaks down, because an offer observed out-of-equilibrium would have to be a sincere clause offered by one of these honest offerors. This, however, brings in other complications; if we also added a number of dishonest offerors for whom $c_{w m}=0$, then the out-of-equilibrium offer might come from one of them, and the No-Offer Equilibrium is revived. See Section 6 for a model of pure adverse selection. 
The equilibrium payoffs are zero in the No-Offer Equilibrium. Its existence, unlike existence of the Mixing Equilibrium, requires no special assumptions.

We can now summarize the possible outcomes of the complete-information model of negotiation. As Table 1 shows, the social surplus - and thus the payoffs for each player, since they split the social surplus - can be Pareto-ranked. The best outcome is when the offeror can be trusted to always offer only sincere clauses, and the next best is when the acceptor can be trusted to always read the clauses offered to him. These are placed above the line in Table 1 because they are really separate games. Of the two equilibria that can exist when precommitment is impossible, the best is the Mixing Equilibrium. Worst of all is the No-Offer Equilibrium, in which an atmosphere of mistrust prevents the acceptor from bothering to even read any clauses that might be offered to him, which results in none being offered.

TABLE 1: THE SOCIAL SURPLUS

\begin{tabular}{ll}
\hline \hline EQUILIBRIUM & TOTAL SURPLUS \\
Honest offeror & $x_{s}+y_{s}-c_{w s}$ \\
Careful acceptor & $x_{s}+y_{s}-c_{w s}-\alpha c_{r}$ \\
\hline & \\
Mixing & $x_{s}+y_{s}-c_{w s}-c_{r}-\frac{c_{r} y_{s}}{y_{m}}$ \\
No Offers & 0 \\
& \\
\hline
\end{tabular}

In the abstract, we cannot pick any one of these four outcomes as being "the equilibrium" of the game. Which outcome should be predicted depends on the particular circumstances. Sometimes reputation on the part of the offeror or of the acceptor will make one of the commitment equilibria the best prediction. In other situations, commitment will not be plausible and we should expect to see one of the last two equilibria, the exact equilibrium depending on expectations. The expectations might in turn depend on history, or on focal points special to the situation being analyzed.

\section{AN ADVERSE SELETION MODEL OF CONTRACT-READING COSTS}

The model described above is one of moral hazard. The problem is that the offeror could always choose the efficient, sincere, clause, but it is not in his interest to do so. Contract-reading costs have important effects in an even simpler model, however, in which a given offeror's contract is either good or bad for the accepter, but not even the offeror knows which. The entire 
model of Section 2 can be used, with just one change: the offeror does not have a choice between a sincere clause and a misleading clause. Rather, with probability $\gamma$ his only choice is between a sincere clause and no offer at all; and with probability $(1-\gamma)$ his only choice is between a misleading clause and no offer at all.

Most of this section will be spent establishing the equilibria of this model. The reader uninterested in these details may skip to the summary at the end of the section.

As in Section 5, it will be useful to start by considering what cannot be true in equilibrium before we go on to describe the actual equilibria.

(a) The acceptor has positive probability of accepting without reading in any equilibrium in which offers are made. Otherwise, the misleading offeror would never offer a clause, which would make the acceptor want to deviate to accepting.

(b) There cannot be a separating equilibrium in pure strategies. It cannot be an equilibrium for the sincere offeror to offer and the misleading offeror not to offer, because then the acceptor would accept without reading, giving the misleading offeror an incentive to offer. It cannot be an equilibrium for the sincere offeror not to offer and the misleading offeror to offer, because then the acceptor would reject without reading and the misleading offeror would deviate to not offering.

(c) If the acceptor mixes between reading and accepting outright, the sincere offeror will offer with probability one. That is because his offer will be accepted either outright or after being read.

(d) The acceptor will not mix between reading and rejecting. Then the misleading offeror would never offer, leading to case (b).

This leaves us with four equilibria. Two varieties are pooling equilibria, in which either both types of offeror offer clauses or both do not offer them. The other two are partially separating equilibria, in which the two types of offerors choose different mixing probabilities and the acceptor mixes either between reading and accepting or between rejecting and accepting.

$$
\text { THE GOOD POOLING EQUILIBRIUM (if } \gamma \geq \operatorname{Max}\left(\frac{y_{m}}{y_{m}+y_{s}}, 1-\frac{c_{r}}{y_{m}}\right) \text { ) }
$$

Offerors: Both types of offeror make offers.

Acceptor: The acceptor accepts without reading. 
Either type of offeror gets a positive payoff if he offers a clause and it is accepted, so to check the equilibrium we only need to determine whether the acceptor will accept rather than reject or read. The acceptor's payoff from accepting without reading is

$$
\pi_{\text {acceptor }}(\text { accept })=\gamma y_{s}-(1-\gamma) y_{m} .
$$

Equilibrium payoff (32) is bigger ${ }^{7}$ than the payoff of zero from rejecting if

$$
\gamma>\frac{y_{m}}{y_{m}+y_{s}} .
$$

The acceptor's payoff from reading is

$$
\pi_{\text {acceptor }}(\text { read })=-c_{r}+\gamma y_{s}-(1-\gamma)(0) .
$$

Deviation payoff (34) is less than equilibrium payoff (32) if

$$
\gamma>1-\frac{c_{r}}{y_{m}} .
$$

\footnotetext{
${ }^{7}$ In the description of the equilibrium, the equivalent of strong inequality (33) is changed to a weak inequality because even an equality supports the equilibrium. To avoid awkward phrasing such as "is no less than" or "is greater than or equal to" here and elsewhere I have used strong inequalities in the proofs.
} 


\section{THE BAD POOLING EQUILIBRIUM}

Offerors: Neither type makes an offer.

Acceptor: The acceptor would reject anything offered.

of-Equilibrium Belief: The acceptor believes the probability that the clause is misleading conditional on it being offered is $\hat{\gamma} \leq \operatorname{Min}\left(\frac{y_{m}}{y_{m}+y_{s}}, 1-\frac{c_{r}}{y_{m}}\right)$.

Since there is a cost to making an offer, neither type of offeror will want to make an offer the acceptor is sure to reject, so the offerors will not deviate.

The acceptor's subjective expected payoff from deviating to accept an out-of- equilibrium offer is

$$
\pi_{\text {acceptor }}(\text { accept })=\hat{\gamma} y_{s}-(1-\hat{\gamma}) y_{m}
$$

Payoff (36) is bigger than the payoff of 0 from rejecting the out-of-equilibrium offer if

$$
\hat{\gamma}<\frac{y_{m}}{y_{m}+y_{s}} .
$$

The expected payoff from deviating to read an out-of-equilibrium offer is

$$
\pi_{\text {acceptor }}(\text { read })=-c_{r}+\hat{\gamma} y_{s}-(1-\hat{\gamma})(0),
$$

which is less than the equilibrium payoff (36) from rejecting if

$$
\hat{\gamma}<1-\frac{c_{r}}{y_{m}} .
$$

There is no pooling equilibrium in which the offeror refrains from making an offer and the acceptor would read an out-of-equilibrium offer. The prospect of having an offer read would deter the misleading offeror but not the sincere offeror, and so break up the pooling behavior. 


$$
\text { THE READING-ACCEPTING EQUILIBRIUM (if } \left.c_{r} \leq \operatorname{Min}\left((1-\gamma) y_{m}, \frac{y_{m} y_{s}}{y_{m}+y_{s}}\right)\right)
$$

Sincere Offeror: The sincere offeror makes an offer.

Misleading Offeror: The misleading offeror makes an offer with probability $\theta_{m}=\frac{\gamma c_{r}}{(1-\gamma)\left(y_{m}-c_{r}\right)}$.

Acceptor: The acceptor accepts with probability $\theta_{a}=\frac{c_{w m}}{x_{m}}$ and otherwise reads the clause and accepts only if it is sincere.

The sincere offeror makes an offer because he knows the acceptor will accept it, with or without reading the clause.

For the misleading offeror to use a mixed strategy, he must be indifferent between making an offer and not making one. This requires that

$$
\pi_{\text {misleading offeror }}(\text { offer })=-c_{w m}+\theta_{a} x_{m}+\left(1-\theta_{a}\right)(0)=\pi_{\text {misleading offeror }}(\text { no offer })=0,
$$

which tells us that

$$
\theta_{a}=\frac{c_{w m}}{x_{m}}
$$

Assumption (1) tells us that expression (41) is less than one, and so can be a probability.

For the acceptor to be willing to mix between reading and accepting requires that he be indifferent between them. With probability $\gamma+\theta_{m}(1-\gamma)$ the offeror makes an offer. Fraction $\frac{\gamma}{\gamma+\theta_{m}(1-\gamma)}$ of those offers are sincere and fraction $\frac{\theta_{m}(1-\gamma)}{\gamma+\theta_{m}(1-\gamma)}$ are misleading. Hence,

$$
\pi_{\text {acceptor }}(\text { accept })=\frac{\gamma}{\gamma+\theta_{m}(1-\gamma)}\left(y_{s}\right)+\frac{\theta_{m}(1-\gamma)}{\gamma+\theta_{m}(1-\gamma)}\left(-y_{m}\right)
$$

and

$$
\pi_{\text {acceptor }}(\text { read })=-c_{r}+\frac{\gamma}{\gamma+\theta_{m}(1-\gamma)}\left(y_{s}\right)+\frac{\theta_{m}(1-\gamma)}{\gamma+\theta_{m}(1-\gamma)}(0) .
$$

Equating these two payoffs yields

$$
\theta_{m}=\frac{\gamma c_{r}}{(1-\gamma)\left(y_{m}-c_{r}\right)} .
$$

This is always positive, and it will be less than one if $c_{r}<(1-\gamma) y_{m}$.

We must also check that the acceptor would not prefer to deviate to rejecting outright. This has a payoff of zero, which must be compared with the equilibrium payoff. The equilibrium payoff can be written from equation (43) and the equilibrium value of $\theta_{m}$ as

$$
\pi_{\text {acceptor }}(\text { read })=-c_{r}+\frac{\gamma}{\gamma+\theta_{m}(1-\gamma)}\left(y_{s}\right)=-c_{r}+\frac{\gamma}{\gamma+\left[\frac{\gamma c_{r}}{(1-\gamma)\left(y_{m}-c_{r}\right)}\right](1-\gamma)}\left(y_{s}\right) .
$$

It turns out that equation (45) is positive if $c_{r}<\frac{y_{m} y_{s}}{y_{m}+y_{s}}$. 


\section{THE ACCEPTING-REJECTING EQUILIBRIUM (if $c_{r} \geq \frac{y_{m} y_{s}}{y_{m}+y_{s}}$ )}

Sincere Offeror: The sincere offeror makes an offer with probability $\theta_{s}$

Misleading Offeror: The misleading offeror makes an offer with probability $\theta_{m}$.

Acceptor: The acceptor accepts the clause with probability $\frac{c_{w s}}{x_{s}}$ and otherwise rejects it.

$$
\begin{aligned}
& \text { If } \gamma \leq \frac{y_{m}}{y_{m}+y_{s}} \text { then } \theta_{s}=1 \text { and } \theta_{m}=\frac{\gamma y_{s}}{(1-\gamma) y_{m}} . \\
& \text { If } \gamma \geq \frac{y_{m}}{y_{m}+y_{s}} \text { then } \theta_{s}=\frac{(1-\gamma) y_{m}}{\gamma y_{s}} \text { and } \theta_{m}=1 \text {. }
\end{aligned}
$$

For the sincere offeror to use a mixed strategy, he must be indifferent between making an offer and not making one. This requires that

$$
\pi_{\text {sincere offeror }}(\text { offer })=-c_{w s}+\theta_{s} x_{s}+\left(1-\theta_{a}\right)(0)=\pi_{\text {sincere offeror }}(\text { no offer })=0,
$$

which tells us that

$$
\theta_{a}=\frac{c_{w s}}{x_{s}}
$$

Assumption (1) tells us that expression (41) is less than one, and so can be a probability.

For the misleading offeror to use a mixed strategy, he must be indifferent between making an offer and not making one. This requires, as in the Reading-Accepting Equilibrium, that

$$
\pi_{\text {misleading offeror }}(\text { offer })=-c_{w m}+\theta_{a} x_{m}+\left(1-\theta_{a}\right)(0)=\pi_{\text {misleading offeror }}(\text { no offer })=0,
$$

which tells us that

$$
\theta_{a}=\frac{c_{w m}}{x_{m}}
$$

Assumption (1) tells us that expression (41) is less than one, and so can be a probability.

Equations (47) and (49) contradict each other unless the parameters take very special values. This tells us that it is almost never true that both types of offerors use mixed strategies in the same equilibrium. So we must look at two cases:

Case 1. Suppose that $\theta_{s}=1$, so the sincere offeror does not mix. For the acceptor to be willing to mix between rejecting and accepting requires that he be indifferent between them. With probability $\gamma+\theta_{m}(1-\gamma)$ the offeror makes an offer. Fraction $\frac{\gamma}{\gamma+\theta_{m}(1-\gamma)}$ of those offers are sincere and fraction $\frac{\theta_{m}(1-\gamma)}{\gamma+\theta_{m}(1-\gamma)}$ are misleading. Hence, just as in the Reading-Accepting Equilibrium,

$$
\pi_{\text {acceptor }}(\text { accept })=\frac{\gamma}{\gamma+\theta_{m}(1-\gamma)}\left(y_{s}\right)+\frac{\theta_{m}(1-\gamma)}{\gamma+\theta_{m}(1-\gamma)}\left(-y_{m}\right) .
$$

Since $\pi_{\text {acceptor }}($ read $)=0$, equating the two equilibrium pure-strategy payoffs yields

$$
\theta_{m}=\frac{\gamma y_{s}}{(1-\gamma)\left(y_{m}\right)}
$$


This is always positive. It will be less than one if $\gamma<\frac{y_{m}}{y_{s}+y_{m}}$.

We must also check that the acceptor would not prefer to deviate to reading the clause. This has an expected payoff of

$$
\pi_{\text {acceptor }}(\text { read })=-c_{r}+\frac{\gamma}{\gamma+\theta_{m}(1-\gamma)}\left(y_{s}\right)+\frac{\theta_{m}(1-\gamma)}{\gamma+\theta_{m}(1-\gamma)}(0)=-c_{r}+\frac{\gamma}{\gamma+\left[\frac{\gamma y_{s}}{(1-\gamma)\left(y_{m}\right)}\right](1-\gamma)}\left(y_{s}\right) .
$$

After simplifying, the acceptor's payoff from reading the clause is less than his equilibrium payoff of zero if

$$
c_{r}>\frac{y_{m} y_{s}}{y_{m}+y_{s}} \text {. }
$$

Case 2. Suppose that $\theta_{m}=1$, so the misleading offeror does not mix. For the acceptor to be willing to mix between rejecting and accepting requires that he be indifferent between them. With probability $\gamma \theta_{s}+(1-\gamma)$ the offeror makes an offer. Fraction $\frac{\gamma \theta_{s}}{\gamma \theta_{s}+(1-\gamma)}$ of those offers are sincere and fraction $\frac{(1-\gamma)}{\theta_{s} \gamma+(1-\gamma)}$ are misleading. Hence,

$$
\pi_{\text {acceptor }}(\text { accept })=\frac{\gamma \theta_{s}}{\gamma \theta_{s}+(1-\gamma)}\left(y_{s}\right)+\frac{(1-\gamma)}{\theta_{s} \gamma+(1-\gamma)}\left(-y_{m}\right) \text {. }
$$

Since $\pi_{\text {acceptor }}($ read $)=0$, equating the two equilibrium pure-strategy payoffs yields

$$
\theta_{s}=\frac{(1-\gamma) y_{m}}{\gamma y_{s}}
$$

This is always positive. It will be less than one if $\gamma>\frac{y_{m}}{y_{m}+y_{s}}$.

We must also check that the acceptor would not prefer to deviate to reading the clause. This has an expected payoff of

$$
\begin{aligned}
\pi_{\text {acceptor }}(\text { read }) & =-c_{r}+\left(\frac{\gamma \theta_{s}}{\gamma \theta_{s}+(1-\gamma)}\right)\left(y_{s}\right)+\left(\frac{(1-\gamma)}{\theta_{s} \gamma+(1-\gamma)}\right)(0) \\
& =-c_{r}+\left(\frac{\gamma\left(\frac{(1-\gamma) y_{m}}{\gamma y_{s}}\right)}{\gamma\left(\frac{(1-\gamma) y_{m}}{\gamma y_{s}}\right)+(1-\gamma)}\right)\left(y_{s}\right) .
\end{aligned}
$$

After simplifying, the acceptor's payoff from deviating to reading the clause is less than his equilibrium payoff of zero if

$$
c_{r}>\frac{y_{m} y_{s}}{y_{m}+y_{s}},
$$

a condition identical to that for Case 1 . 
Summary of the Adverse Selection Model

There are four possible equilibria. Under any parameters, the Bad Pooling Equilibrium exists, in which no offers are made because any that were offered would be rejected. If the proportion of sincere offerors is high enough, the Good Pooling Equilibrium exists, in which the offeror always offers and the acceptor accepts without reading. If the reading cost is low enough, the Reading-Accepting Equilibrium exists, in which both types of offers are made to some extent (but some misleading offerors make no offer) and the acceptor mixes between reading and accepting outright. If the reading cost is too high for the Reading-Accepting Equilibrium, the Rejecting-Accepting Equilibrium exists: the acceptor mixes between reading and accepting, but never reads. Both types of offers are made, with one type of offeror or the other mixing between offering and not offering.

The Bad Pooling Equilibrium is the equivalent of the No-Offer Equilibrium in the moral hazard model, and the Reading-Accepting Equilibrium is the equivalent of the Mixed-Strategy Equilibrium. The Good Pooling and Rejecting-Accepting Equilibria do not have such close equivalents in the moral hazard model, since in that model if the acceptor never reads, the offeror will always choose the misleading clause.

The usefulness of the adverse selection model is to show that contract- reading costs are not important just because of moral hazard, the possibility that one party to a contract deliberately chooses to be opportunistic. Contract-reading costs affect the situation in roughly the same way whether a model is based on moral hazard or o adverse selection. It is not the offeror's choice between sincere and misleading clauses, but two other things which drive the outcome in either kind of model: (a) the offeror must decide between offering and not offering a new clause, and (b) the acceptor must decide to read or not read, knowing that both sincere and misleading clauses are possible.

The correspondence between the two model is not exact because behavior in the adverse selection model is more constrained by the assumptions: there is no possibility of either all clauses being sincere or none being sincere. Since not every offer can be sincere, the first-best surplus is less than in the moral hazard model. For this reason, commitment to reading clauses is not so useful under adverse selection. It can, to be sure, avoid the Bad Pooling Equilibrium, but the benefit depends on the proportion of sincere offerors in the population (the $\gamma$ parameter). If that proportion is low enough, the cost of reading, $c_{r}$, can even be greater than the benefit of escaping the Bad Pooling Equilibrium, $\gamma y_{s}$, yielding a negative payoff, so the acceptor would not want to commit to reading offered clauses. The other effect of ruling out extreme proportions of misleading or sincere clauses is that since not every offer can be misleading, the acceptor is less vulnerable than under moral hazard. That is why in the adverse selection model the acceptor is willing to follow the equilibrium behavior of the Good Pooling and Rejecting-Accepting Equilibria; if the acceptor never reads clauses but does accept them sometimes, some of the accepted clauses will still be sincere, unlike in the moral hazard model.

Both models have as equilibria the extreme result that no offeror offers a clause because the 
acceptor would reject any clause offered without reading it. The resulting inefficiency is less in the adverse selection model. In the moral hazard model, the offeror could always offer a sincere clause, so when he offers a misleading clause there is an opportunity cost. In the adverse selection model, the offeror who offers a misleading clause could not have offered a sincere one, so the inefficiency is less-contractual incompleteness is sometimes efficient in the adverse selection model. In both models, however, the pessimistic equilibrium results in the loss of all the possible gains from adding extra clauses to contracts and thus explains inefficient incomplete contracts.

\section{INTERPRETATION}

The Introduction asked the question of why contracts are incomplete, and the model above has shown that contract-reading costs can give the answer. The model has other things to teach, however. Most fundamentally, even if the parties to a contract cannot trust each other, negotiation still increases welfare. Lengthy dealmaking sessions are not necessarily inefficient: to the extent that they add mutually beneficial details to the deal, they are efficient. Dealmakers are productive members of society, and quick agreement is not necessarily a sign of efficiency. In the No- Offer Equilibrium, quick and simple agreement is a sign of extreme inefficiency. Since negotiation, as opposed to simple bargaining over shares of a surplus, enhances efficiency, it is worth considering what encourage negotiation. Below I will lay out ten lessons of the model for law and business.

1. Contract-reading costs matter as much as contract-writing costs. Although the contract-writing costs, $c_{w s}$ and $c_{w m}$, have an influence in this model, not much would change if they were set to zero. As Table 1 shows, these costs are simply subtracted from the social surplus like any simple transactions cost. The contract-reading cost, $c_{r}$, is much more important. It has an indirect effect, via the subtraction of $\frac{c_{r} y_{s}}{y_{m}}$, as well as a direct effect. This effect is still continuous in $c_{r}$, so if contract-reading costs are small, it might seem that their effect on welfare is also low. The contract-reading cost has a second impact, however: it generates multiple equilibria. The contract-reading cost, in combination with pessimistic expectations, can lead to the No-Offer Equilibrium, in which the benefit from the sincere clause is entirely lost. The ultimate effect of a contract-reading cost of $c_{r}$ can then be much greater than the magnitude of $c_{r}$ itself. Lumping all "transaction costs" together- contract-reading and contract-writing costs both - is inappropriate. A small contract-reading cost can destroy the entire gains from trade.

Contract-reading costs are both realistic and hard to eliminate. It is relatively easy to write fifty new pages for a contract to provide for extra contingencies but it is quite difficult for the reader to be sure what those fifty pages contain. Standard "boilerplate" contracts, written for no particular transaction and pulled out once a contract must be executed, are a good solution for 
the problem of contract-writing costs, but not for contract-reading costs. ${ }^{8}$ The accepting side of the contract still does not know what the boilerplate contains and must worry about whether it is pure boilerplate or boilerplate with some non-standard clauses cleverly hidden inside.

2. Legal default rules, or even mandatory rules are important to overcome contract-reading costs. One view of contract law is that its importance is limited by the possibility that parties can always replace the legal defaults with their own contract terms, limiting the loss from inefficient laws to the contract-writing cost incurred when everyone replaces them with customized terms. The model shows, howver, that legal default rules are important for more than just to save contractwriting costs. If an efficient default rules is in place, the two parties often will not need the sincere clause of the model - it will be automatically added by a neutral third party, the law, unless they took steps to remove it. The default rule is important for much more than just saving the $\operatorname{costs} c_{r}$ and $c_{w s}$. Even if the contract-reading and contract-writing costs are small, the default rule is important, because it replaces the negotiation game. This is similar to the conclusions of various models of strategic contracting under incomplete information-see Ayres \& Gertner $(1989,1992)$, Hermalin \& Katz (1993), and Jason Johnston (1990), but here the strategic behavior does not arise from incomplete information but from the contract clause itself.

One might go further and use this model to argue for mandatory contract rules, which override whatever may be written in the contract. If it is practical for a court to determine that a clause is misleading, the best solution is for courts to refuse to enforce such clauses. Courts do this to some extent, refusing to enforce suspicious fine print, which is the subject of the 1990 Katz article discussed in the Introduction.

The disadvantage of legal default and mandatory rules is, of course, that they reduce the flexibility of the contract. If different "sincere clauses" are appropriate for different contracts, it is difficult for courts to choose which clause should be used, as Alan Schwartz (1993) emphasizes. Often, the parties will not find the legal default rule efficient and the courts will not be able to tell whether a clause was exante fair to the acceptor or not.

3. A reputation for honesty in negotiation is a valuable asset. The contracting parties do best if the offeror is intrinsically honest, the case of precommitment to offering sincere clauses analyzed in Section 3. His honesty does not eliminate the contract-writing cost, but it does eliminate the need to read the contract and it allows efficient clauses to be added. Any player who has established a reputation for honesty will be an attractive business partner and be offered more attractive contracts.

4. Good fences make good neighbors. It is better to deal with someone who is on guard against you. Even if the offeror cannot be trusted to be honest in the absence of external influences, if the acceptor can commit to always reading the offers, welfare is almost as high, as Section 4 showed. The

\footnotetext{
${ }^{8}$ The Web now has many sites offering boilerplate. Some offer them for free, e.g., Legal-Forms-Kit.com, http:/ /www.legal-forms-kit.com/freelegalforms.html (August 15, 2001), and some at a price, e.g., Legal-Forms.ca, http://www.contracts-on-demand.com/ (August 15, 2001).
} 
offeror actually prefers to deal with an acceptor who always reads clauses, because he need not worry about pessimistic expectations which would cause the acceptor to dismiss his offers without serious consideration.

5. Corporate lawyers are worth their salary even if they never discover flaws in contracts. Point (4) implies that reading is valuable even if it never reveals anything untoward. The purpose of a company's legal staff is to deter the other side from trying to be sly or dishonest, and if the staff's lawyers are well enough respected, they will never discover any dishonesty. The corporate counsel's veto of a contract term is like the atomic bomb, most useful when not used. This supplements the list of reasons-which in the context of this paper amount to finding Paretoimproving clauses- that Ronald Gilson (1984) lays out for why corporate lawyers are socially useful.

6. A mistrustful attitude in negotiations can be self-enforcing. If a model has multiple equilibria, that means that expectations are important to the outcome. If the acceptor expects the offeror to offer only misleading clauses, he will not bother to read any clauses that are offered, and so the offeror will offer none. This is the worst case from the point of view of both parties, and changing the expectations-however that might be done-is an important prerequisite to negotiations.

7. Inefficient work rules can persist indefinitely in union labor contracts, even when both union and management recognize that Pareto improvements are possible. Some socially inefficient union work rules can be explained in terms of redistribution within the union, e.g., "no show" featherbedding jobs which can be used by a union to reward certain members. Others, however, such as trains being required to carry double the needed crew, truck drivers being forbidden to help unload trucks, and painters not being allowed to use spray guns of certain widths are harder to explain. ${ }^{9} \mathrm{~A}$ corollary of result (6) is that when labor and management mistrust each other, they may continue to renew a contract known to be inefficient rather than trying to propose improvements which the other side might believe were really attempts to sneak an advantage.

8. Forcing the parties to come to the bargaining table can help them. A common feature of labor laws is a requirement that labor and management come to the bargaining table and negotiate "in good faith". ${ }^{10}$ This does not mean that they must make offers acceptable to each other, only that they must talk, so it seems a peculiar and useless requirement. The negotiation model suggests it is not, because it may serve as a requirement that the parties read each other's offers, which can raise welfare by overcoming pessimistic out-of-equilibrium beliefs.

\footnotetext{
${ }^{9}$ These and other examples can be found in Reynolds (1987) starting at page 107.

${ }^{10}$ Section 8(d), 29 U.S.C. @ 158(d) (1988) defines the duty to bargain as "the mutual obligation of the employer and the representative of the employees to meet at reasonable times and confer in good faith with respect to wages, hours, and other terms and conditions of employment . . . but such obligation does not compel either party to agree to a proposal or require the making of a concession." A representative lawsuit is NLRB v. Billion Motors, Inc., 700 F.2d 454, 456 (8th Cir. 1983), in which a union complained that the company's negotiator was unprepared, failed to show up to meetings, made sham proposals, and announced impasse prematurely. For a legal discussion by an economist that discusses the usefulness of the duty to bargain in generating information, see Keith Hylton (1994).
} 
9. Warranties cannot entirely solve the problem of product quality. Product quality is not so serious a problem as contract terms, because if the quality were the only problem, warranties could be provided. The quality of the warranty itself, however, is also in question. The warranty's fine print may take back what opening sentences seem to provide. One cannot have a warranty of the warranty; at best, the law must fall back on canons of construction such as that vague contracts are construed against the writer.

The negotiation model could be adapted to a situation in which product quality is uncertain but the buyer can inspect the product at low cost. This inspection might simply take the form of reading promotional materials provided by the seller, if the law provided penalties for sellers who lie. The model suggests that expectations will determine the outcome, and that the equilibrium may be in mixed strategies. It may also result in no information being provided because the buyer, being pessimistic, would not go to the effort of inspecting it anyway. In such a case, the seller would have to provide incentives for the buyer to incur the costs of inspecting or reading. ${ }^{11}$

10. Offers and mechanisms that are theoretically attractive will be rejected by rational agents if they are too complicated. Two standard puzzles for economists are why more complex contracts are not used in practice and why experimental subjects reject complex offers that yield high expected utility. Mechanisms of the kind discussed in Tirole (1999) can achieve the first-best under surprisingly poor informational conditions, but the mechanisms are often complicated, involving a menu of contracts and coordination of Nash expectations when there are multiple equilibria. Real-world contracts may involve many contingencies, but they are rarely as difficult to design or understand as these mechanisms. Also, numerous puzzles in the psychology of decision making contradict expected utility theory because experimental subjects choose simple offers that yield them lower utility. The two best known are perhaps the Allais Paradox and the Ellsberg Paradox. Both of these involve the typical subject preferring simple offers to more complicated offers that would yield them higher expected utility,where it is the clever design of the offers that allows us to make that claim about their utility function. ${ }^{12}$

Contract-reading costs help explain both phenomenon. In this article's model, a complex contract is a contract with one extra clause added. Complex mechanisms may be theoretically ideal, but only in a world where the parties to the mechanism can understand them costlessly. Otherwise, the acceptor of such a mechanism rationally fears that the complexity hides something that is to his disadvantage and to the offeror's advantage. The puzzles of decisionmaking are similar. When someone makes an intricate offer-probabilities of probabilities, for example,

\footnotetext{
${ }^{11}$ We are beginning to see advertisers paying consumers to read advertisements on the Internet. See "Are Advertisers Ready to Pay Their Viewers?" Wall Street Journal, Bart Ziegler, November 14, 1996, reprinted as pages 218-220 of Readings in Games and Information, Eric Rasmusen, editor, Oxford: Blackwell Publishers, 2001.

${ }^{12}$ For descriptions of the paradoxes see pages 163-167 of Dawes (1988). Dawes notes that decision theorists have tried to introduce new axioms of decision that essentially add pessimism, but "the assumption of pessimism implies the belief that one's choice somehow affects the probabilities of the consequences" (p. 167). That, of course, is what mistrust of the offeror is all about.
} 
as in the Ellsberg Paradox-the acceptor rationally is apprehensive. This is true even in an experimental setting, in which the offeror seems unlikely to be trying to maximize profits, since experimenters are notorious for trying to trick subjects into making wrong decisions. The simple choice may be the wrong choice, but at least its degree of wrongness is limited since it is understandable.

\section{CONCLUDING REMARKS}

After the long list of lessons in Section 7, it may be helpful for me to summarize the basics of this article. Much real-world contracting involves finding new clauses to add to a basic agreement, clauses which may or may not increase the welfare of both parties. The parties must decide which complications to propose, how closely to examine the other side's proposals, and whether to accept them. In this article, negotiation has been modelled as an auditing game in which one player offers a clause that the other player may or may not examine carefully. The model suggests a reason why contracts are incomplete: contract-reading costs matter as much as contract-writing costs. Fine print that is cheap to write can be expensive to read carefully enough to detect the absence of trap clauses artfully written to benefit the writer. As a result, complicated clauses that purport to benefit both parties may be rejected outright even if they really do benefit both parties, and contract is left incomplete.

\section{Contact Information and Acknowledgements}

Eric B. Rasmusen is Professor of Business Economics and Public Policy and Sanjay Subhedar Faculty Fellow, Indiana University, Kelley School of Business, BU 456, 1309 E. 10th Street, Bloomington, Indiana, 47405- 1701. Office: (812) 855-9219. Fax: 812-855-3354. Erasmuse@indiana.edu. Php.indiana.edu/ erasmuse.

Professor Rasmusen thanks Maria Arbatskaya, William Bright, Lutz Busch, Peter Cramton, Kenneth Elzinga, T. Lynn Fisher, Benjamin Hermalin, Michihiro Kandori, Felice Martinello, Wolfgang Pesendorfer, J. Mark Ramseyer, David Waterman, two anonymous referees and participants in seminars at Brock University, CIRANO (Montreal), Indiana University, the U. S. Department of Justice, Kyushu University, the University of Manitoba, Otaru University of Commerce, the Central Bank of Turkey, Virginia Polytechnic Institute, the University of Virginia, and the American Law and Economics Association for helpful comments. I thank Harvard Law School's Olin Center and the University of Tokyo's Center for International Research on the Japanese Economy for their hospitality. Not all of those I thank have seen this draft, and they bear no responsibility for errors. 


\section{REFERENCES}

Avenhaus, Rudolf, Bernhard von Stengel \& Shmuel Zamir (2002), "Inspection Games, " from Volume III of The Handbook of Game Theory, edited by Robert Aumann and Sergiu Hart, forthcoming.

Ayres, Ian \& Robert Gertner (1989) "Filling Gaps in Incomplete Contracts: An Economic Theory of Default Rules," Yale Law Journal, 99: 87-130 (October 1989).

— \& - (1992) "Strategic Contractual Inefficiency and the Optimal Choice of Legal Rules," Yale Law Journal, 101: 729-773 (January 1992).

Baiman, Stan and Joel Demski (1980) "Economically Optimal Performance Evaluation and Control Systems," Journal of Accounting Research, 18: 184-220 (Supplement 1980).

Bernheim,B.-Douglas \& Michael D. Whinston (1998) "Incomplete Contracts and Strategic Ambiguity," American Economic Review, 88: 902-32 (September 1998).

Cho, In-Koo \& David Kreps (1987) “Signaling Games and Stable Equilibria," Quarterly Journal of Economics, 102: 179-221 (May 1987).

Chung, Tai-Yeong (1991) "Incomplete Contracts, Specific Investments, and Risk Sharing," Review of Economic Studies, 58: 1031-1042 (October 1991).

Dawes, Robyn (1988) Rational Choice in an Uncertain World, San Diego: Harcourt, Brace, Jovanovich Publishers, 1988.

Dresher, Melvin (1962) "A Sampling Inspection Problem in Arms Control Agreements: A Game-Theoretic Analysis," Memorandum No. RM-2972-ARPA, RAND Corporation, Santa Monica, California.

Gilson, Ronald (1984) “Value Creation by Business Lawyers: Legal Skills and Asset Pricing," Yale Law Journal 94: 244-313 (December 1984).

Hart, Oliver \& John Moore (1988) "Incomplete Contracts and Renegotiation," Econometrica, 56: 755-786 (July 1988).

Hermalin, Benjamin E. \& Michael L. Katz, "Judicial Modification of Contracts between Sophisticated Parties: A More Complete View of Incomplete Contracts and Their Breach," Journal of Law, Economics, \& Organization, 9: 230-255 (October 1993).

Holmstrom, Bengt \& Paul R. Milgrom (1991) "Multi-Task Principal Agent Problems: Incentive Contracts, Asset Ownership and Job Design," Journal of Law, Economics, and Organization, 7: 24-52 (Special issue, 1991).

Hylton, Keith (1994) "An Economic Theory of the Duty to Bargain," Georgetown Law Journal, 
83: 19-76 (November 1994).

Johnston, Jason (1990) "Strategic Bargaining and the Economic Theory of Contract Default Rules," Yale Law Journal, 100: 615-657 (December 1990).

Katz, Avery (1990) "Your Terms or Mine? The Duty to Read the Fine Print in Contracts," RAND Journal of Economics, 21: 518-537 (Winter 1990).

Kennan, John \& Robert Wilson (1993) “Bargaining with Private Information," Journal of Economic Literature, 31: 45-104 (March 1993).

Lulfesmann, Christoph (2001) "Incomplete Contracts, Non-Contractible Quality, and Renegotiation,"Contributions to Theoretical Economics, 1: 2. http://www.bepress.com/bejte/contributions/vol

Macaulay, Stewart (1963) "Non-Contractual Relations in Business: A Preliminary Study," American Sociological Review, 28: 55-67 (February 1963).

Myerson, Roger \& Mark Satterthwaite (1983) "Efficient Mechanisms for Bilateral Trading," Journal of Economic Theory, 29:1-21 (April 1983).

Rasmusen, Eric (1993) "Lobbying When the Decisionmaker Can Acquire Independent Information," Public Choice 77: 899-913.

-(2001) Games and Information: An Introduction to Game Theory, Third edition (first edition 1989). Oxford: Blackwell Publishing, 2001.

Reynolds, Morgan (1987) Making America Poorer: The Cost of Labor Law, Washington: Cato Institute, 1987.

Schwartz, Alan (1993) "The Default Rule Paradigm and the Limits of Contract Law," Southern California Interdisciplinary Law Journal, 3: 390-419 (Fall 1993).

Sebenius, James (1992) "Negotiation Analysis: A Characterization and Review," Management Science, 38: 18-38 (January 1992).

Spier, Kathryn (1992) "Incomplete Contracts and Signalling," RAND Journal of Economics, 23: 432-43 (Autumn 1992).

Stigler, George (1980) "An Introduction to Privacy in Economics and Politics," Journal of Legal Studies, 9: 623-644 (December 1980) .

Tirole, Jean (1999) “Incomplete Contracts: Where Do We Stand?" Econometrica 67: 741-781 (July 1999).

Townsend, Robert (1979) "Optimal Contracts and Competitive Markets with Costly State Verification," Journal of Economic Theory, 21: 265-293 (October 1979). 
Van Damme, Eric (1989) "Stable Equilibria and Forward Induction," Journal of Economic Theory, 48: 476-496 (August 1989). 